\title{
Correction to: Material and Mechanical Characterization of Multi-Functional Carbon Nanotube Reinforced Hybrid Composite Materials
}

\author{
A. Paul Praveen ${ }^{1} \cdot$ V. Rajamohan ${ }^{2} \cdot$ A.T. Mathew ${ }^{1}$ \\ Published online: 14 July 2020 \\ (C) The Society for Experimental Mechanics, Inc 2020
}

Correction to: Experimental Techniques (2019) 43:301-314. https://doi.org/10.1007/s40799-019-00316-0

In the original article, the first author A. Paul Praveen's name was mentioned incorrectly in the author list. The details given in this correction are correct.

Publisher's Note Springer Nature remains neutral with regard to jurisdictional claims in published maps and institutional affiliations.

The online version of the original article can be found at https://doi.org/ 10.1007/s40799-019-00316-0

\footnotetext{
V. Rajamohan

vasudevan.r@vit.ac.in

1 School of Mechanical Engineering, Vellore Institute of Technology (VIT), Vellore, Tamil Nadu 632014, India

2 Centre for Innovative Manufacturing and Research (CIMR), VIT, Vellore 632014, India
} 